\title{
Extravascular Volume Overload
}

National Cancer Institute

\section{Source}

National Cancer Institute. Extravascular Volume Overload. NCI Thesaurus. Code C161588.

Fluid volume expansion that occurs outside of the vascular system, which may be characterized by peripheral edema, pleural effusion, ascites, and pericardial effusion. 